\title{
İdyopatik Harlequin Sendromlu Nadir Bir Olgu
}

\author{
Saadet Sayan
}

Sakarya Üniversitesi Tıp Fakültesi, Eğitim ve Araştırma Hastanesi, Sakarya, Türkiye

Saadet Sayan, Uzm. Dr.
İletişim:

Uzm. Dr. Saadet Sayan

Sakarya Üniversitesi Tıp Fakültesi, Eğitim ve Araştırma Hastanesi, Sakarya, Türkiye Tel: +90 2648884000

E-Posta:dr_sdt.86@hotmail.com
Gönderilme Tarihi : 07 Eylül 2017

Revizyon Tarihi : 190cak 2018

Kabul Tarihi : $\quad 210$ cak 2018
ÖZET

Harlequin sendromu, yüzde unilateral anhidrozis ve mat cilt rengine kontralateral hiperhidrozis ve kızarıklığın eşlik ettiği nadir bir sempatik sinir sistemi hastalığıdır. Çevresel ve/veya emosyonel stres ile belirginleşen hastalık, çoğunlukla tedavi gerektirmez ve benign bir otonom disfonksiyondur. Travmatik ya da dejeneratif süreçler tabloya yol açsa da çoğunlukla etyolojik neden bulunamaz. 42 yaşındaki kadın olgumuz, Isı artışı ve stres anında, göz bulgularının (ptozis, anormal pupil vb.) eşlik etmediği, yüz sağ yarımında aşırı terleme, kızarma ile başvurmuşdu. Travma veya cerrahi girişim öyküsü olmayan hastanın beyin, servikal ve torakal görüntülemelerinde etyolojik bir neden saptanmadı. Şikayetleri sosyal ilişkilerini etkileyecek düzeye ulaşan hasta semptomatik tedavi amacıyla sempatik ganglion blokajına yönlendirildi. Olgumuz nadir olarak karşılaşılan idyopatik harlequin sendromuna dikkat çekmek amacıyla sunulmuştur.

Anahtar kelimeler: Idyopatik, harlequin sendromu

\section{A RARE CASE OF IDIOPATHIC HARLEOUIN SYNDROME}

\section{ABSTRACT}

Harlequin Syndrome is a rare malady of the sympathetic nervous system which is accompanied by unilateral anhydrosis and dull skin of the face, contralateral hyperhidrosis and flushing. It is a benign autonomic dysfunction which becomes more pronounced with environmental and/or emotional stress and generally requires treatment. Although traumatic and degenerative processes lead to the syndrome, mostly there are no etiologic factors. A 42 years-old-woman presented with hyperhidrosis and flushing of unilateral of the face without ocular findings (ptosis, myosis, etc.), in the time of stress and/or thermo-rising. There was no history of trauma or surgery. Magnetic resonance imaging of the brain, cervical spine or thoracal spine were normal. A complaint becomes to the level of interfering with social intercourse/life so the patient was referred to sympathetic ganglion blockage for symptomatic treatment. We present the case to aim or(The aim of presenting this case is to call attention to a rarely encountered case of idiopathic harlequin syndrome.

Keywords: Idiopathic, harlequin

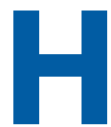
arlequin Sendromu; yüzün asimetrik terlemesi ve kızarması ile karakterize nadir bir otonom sinir sistemi hastalığıdır (1). Genellikle egzersiz, ısı artışı, emosyonel stresle belirginleşen tablo, servikal sempatik zincirin vazomotor ve sudamotor liflerindeki hasara ikincildir (2). Travma, cerrahi girişim gibi invazif nedenler, nörodejeneratif ya da serebrovasküler hastalıklar etyolojide yer alabilse de birçok vaka idyopatik olarak kalmaktadır (3). Burada idyopatik harlequin sendromlu bir olgu paylaşılmıştır. 


\section{Olgu}

Kırk-iki (42) yaşındaki kadın hasta, yüzünün sağ yarımında, aşırı terleme ve kızarma şikayeti ile başvurdu. Yakınmalarının ortam ısısı yükseldiğinde ya da heyecanlanma, endişe duyma gibi stresli durumlarda arttığı ve sosyal ilişkilerine engel olduğu öğrenildi. Hastanın öz geçmişinde bilinen sistemik hastalığı, ilaç kullanımı, geçirilmiş operasyonu ya da travma öyküsü yoktu. Fizik muayenesinde, yüz sağ yarısında ciddi terleme bulguları, hafif kızarıklık mevcut iken yüz diğer yarısı mat ve kuru görünümde idi (Şekil 1). Nörolojik muayenesinde, pupiller izokorik, IR+/+, IIR+/+, göz hareketleri her yöne serbest iken pitozis ya da anormal pupil bulgusu yok idi (Şekil 2, 3). Motor ve duyu muayenesi, serebeller sistem incelemesi ve derin tendon refleksleri doğal idi. Beyin, servikal, üst torakal spinal manyetik rezonans görüntülemesi, torasik sempatik zinciri içeren bilgisayarlı tomografi normal sınırlarda idi (Şekil 4). Olgumuz öyküsü, klinik değerlendirmesi, görüntüleme özellikleriyle idyopatik harlequin sendromu olarak değerlendirildi. Özellikle aşırı terlemeden şikayetçi olan hastamız sempatik ganglion blokajı açısından ileri bir merkezde anestezi kliniğine yönlendirildi.

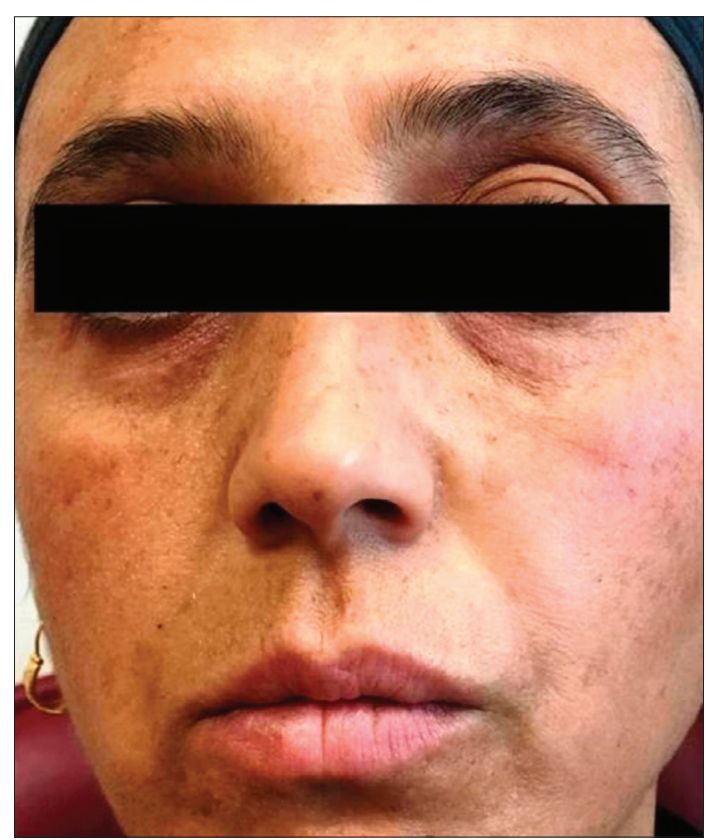

Şekil 1. Yüz sağ yarımında aşırı terleme

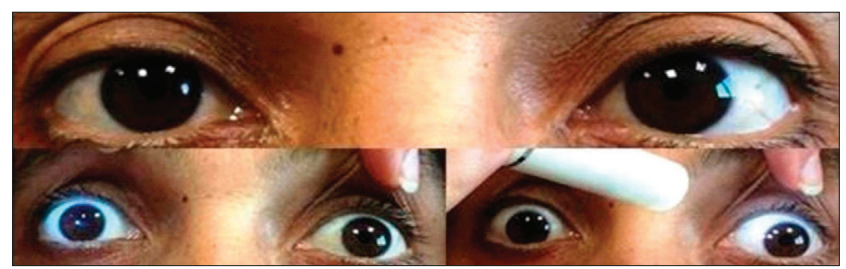

Şekil 2. Bilateral normal pupil

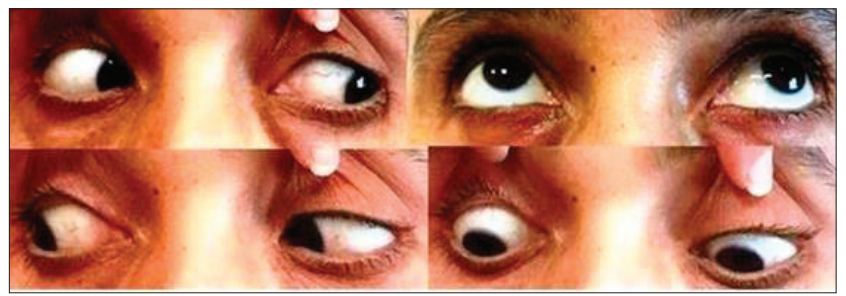

Şekil 3. Göz hareketleri her yöne serbest

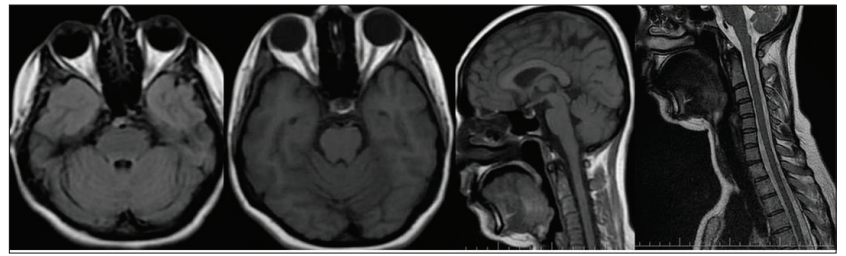

Şekil 4. Normal kranyal, servikal-üst torakal spinal manyetik rezonans görüntüleme

\section{Tartışma}

Harlequin Sendromu ilk kez 1988 yılında Lance ve arkadaşları tarafından, egzersiz, Isı artışı ve stres ile tetiklenen, belirgin sınır hattı oluşturacak düzeyde, yüzün bir yarısının kızarık ve terli diğer yarısının mat ve kuru olması şeklinde tanımlanmıştır (1). Sendrom kadınlarda daha yaygındır ve kliniğe çoğunlukla anormal pupil \{holmes adie sendromu (tonik pupil, arefleksi), horner sendromu (pitozis, miyozis, anhidrozis)\} de eşlik eder $(4,5)$. Bu yüzden olgular tonik pupil, miyotik pupil, pitozis, derin tendon refleks varlığı veya yokluğu açısından dikkatle değerlendirilmelidir. Kadın olgumuzun sağ yüz yarımındaki aşııı terleme ve kızarıklık yakınmasına, nörolojik muayenesinde normal pupil yanıtı ve normoaktif derin tendon refleksleri eşlik etmekte idi.

Harlequin Sendromu, yüzün unilateral pre- ve/veya post ganglionik sempatik vazomotor ve sudamotor sinir liflerinin denervasyonuna ikincil gelişir (6). Yüze ait sempatik lifler, hipotalamustan orjin alır, spinal kordun lateral hornunda sinaps yapar ve pre-ganglionik lifleri oluşturarak T2-3 düzeyinde spinal kordu terk eder. Sempatik zincir içinde ilerleyen vasomotor ve sudamotor lifler, superior servikal ganglionda sinaps yapar ve post-ganglionik lifler olarak karotid pleksus içinde ilerler. Yüzün frontal ve oftalmik bölgesinin sempatik lifleri internal karotid arter çevresinde, maksillar ve mandibular bölgenin sempatik lifleri eksternal karotid arter çevresinde yoğunlaşmıştır. Bu yol üzerinde unilateral sempatik bir denervasyon, çevresel veya emosyonel bir stres durumunda, yüzün bir yarımının aşırı terli ve kızarık, diğer yarımının kuru ve donuk görünümüne yol açacaktır.

Harlequin Sendromu yaygın olarak idyopatik özellik gösterse de, sempatik lifleri baskılayan tümöral ve/veya 
vasküler oluşumlar, beyin sapı lezyonları, siringomiyeli, gullian-barre sendromu, diyabetik otonomik nöropati, mutiple skleroz, invazif girişimler gibi heterojen dağılım gösteren hastalıklara ikincil de görülebilir $(3,7)$. Bu nedenlerin dışlanmasında, beyin ve servikal ve torakal görüntüleme yöntemleri önemlilik gösterir (8). Olgumuzun geçirilmiş travma ya da cerrahi girişim öyküsü yoktu, beyin ve servikotorasik manyatik rezonans görüntülemeleri normal sınırlarda idi.

İdyopatik Harlequin Sendromu genellikle medikal ya da cerrahi tedavi gerektirmeyen benign bir tablodur. Ancak

\section{Kaynaklar}

1. Lance JW, Drummond PD, Gandevia SC, Morris JG. Harlequin syndrome: the sudden onset of unilateral flushing and sweating. J Neurol Neurosurg Psychiatry 1988;51:635-42. [CrossRef]

2. Kaur S, Aggarwal P, Jindal N, Dayal S, Jairath V, Jain VK, Virdi S. Harlequin syndrome: a mask of rare dysautonomic syndromes. Dermatol Online J 2015;21. pii: 13030/qt3q39d7mz.

3. Boling B, Key CC, Wainscott J, Rebel AE. Harlequin Syndrome as a Complication of Epidural Anesthesia. Crit Care Nurse 2014;34:57-61. [CrossRef]

4. Willaert WIM, Scheltinga MRM, Steenhuisen SF, Hiel JA. Harlequin Syndrome: two new cases and a management proposal. Acta Neurol Belg 2009;109:214-20.

5. Bremner F, Smith S. Pupillographic Findings in 39 Consecutive Cases of Harlequin Syndrome. J Neuro-Ophthalmol 2008;28:171-7. [CrossRef] kontralateral kompansatuar aşırı terleme ve kızarmayı engellemek amacıyla ganglion blokajı veya botilinum enjeksiyonu uygulanabilir $(9,10)$. Olgumuz yakınmalarının günlük hayatını engelleyecek boyuta ulaşması nedeniyle ileri merkezde sempatik ganglion blokajına yönlendirildi.

İdyopatik Harlequin sendromu tanısı alan olgumuz anormal pupil yanıtının eşlik etmemesi ve tedavi gerektirecek kadar belirgin otonom bulgulara sahip olması yönüyle bu sendroma dikkat çekmek ve lietatüre katkı sağlamak amacıyla sunulmuştur.

6. Drummond PD, Lance JW. Site of autonomic deficit in Harlequin syndrome: local autonomic failure affecting the arm and the face. Ann Neurol 1993;34:814-9. [CrossRef]

7. Jain $P$, Arya R, Jaryal A, Gulati S. Idiopathic harlequin syndrome: a pediatric case. J Child Neurol 2013;28:527-30. [CrossRef]

8. Wasner G, Maag R, Ludwig J, Binder A, Schattschneider J, Stingele $\mathrm{R}$, Baron R.. Harlequin syndrome - one face of many etiologies. Nat Clin Pract Neurol 2005;1:54-9. [CrossRef]

9. Reddy H, Fatah S, Gulve A, Carmichael AJ. Novel management of harlequin syndrome with stellate ganglion block. $\mathrm{Br} J$ Dermatol 2013;169:954-6. [CrossRef] 1

10. Manhães RK, Spitz M, Vasconcellos LF. Botulinum toxin for treatment of Harlequin syndrome. Parkinsonism Relat Disord 2016;23:112-3. [CrossRef] 